\title{
Do the plants in functional green walls contribute to their ability to filter particulate matter?
}

\section{${ }^{1}$ Plants and Environmental Quality Research Group, Faculty of Science, University of} Technology Sydney

${ }^{2}$ School of Electrical, Mechanical and Mechatronic Systems, Faculty of Engineering and Information Technology, University of Technology Sydney

University of Technology Sydney, P.O. Box 123, Broadway, NSW 2007, Australia *Corresponding author: Thomas.Pettit@uts.edu.au

\begin{abstract}
Indoor air quality has become a growing concern as people are spending more time indoors, combined with the construction of highly sealed buildings that promote thermal efficiency. Particulate matter (PM) is a common indoor air pollutant, with exposure to high concentrations associated with several detrimental health outcomes. Active botanical biofilters or functional green walls are becoming increasingly efficient and have the potential to mitigate high suspended PM concentrations. These systems, however, require further development before they become competitive with industry standard in-room air filters. Whilst the plant growth substrate in active biofilters can act as a filter medium, it was previously not known whether the plant component of these systems played a function in PM filtration. This study thus examines the influence of the botanical component on active green wall PM single pass removal efficiency (SPRE), with a focus on evaluating the air filtration features of different plant species in green wall modules. All tested botanical biofilters outperformed biofilters that consisted only of substrate. Green walls using different plant species had different single pass removal efficiencies, with fern species recording the highest removal efficiencies across all measured particle sizes (Nephrolepis exaltata bostoniensis SPRE for $\mathrm{PM}_{0.3-0.5}$ and $\mathrm{PM}_{5-10}=45.78 \%$ and $92.46 \%$ respectively). Higher removal efficiencies were associated with increased pressure drop across the biofilter. An assessment of plant morphological data suggested that the root structure of the plants strongly influenced removal efficiency. These findings demonstrate the potential to enhance active botanical biofiltration technology with appropriate plant species selection.
\end{abstract}

Keywords: air quality; PM; phytoremediation; active green wall; sustainable buildings; living wall

\section{Highlights}

- Active botanical biofilters can reduce ambient atmospheric particulate matter concentrations.

- Particulate matter removal efficiency is influenced by active green wall plant species.

- Removal efficiency is correlated with pressure drop across the green wall module. 
- Plants with fibrous roots have higher removal efficiencies than tap root species.

\subsection{Introduction}

Indoor air quality has become a growing concern, as urban people spend the majority of their time indoors [1]. With a rapidly increasing shift towards greater urbanisation globally [2], a significant portion of population exposure to air pollutants occurs within an indoor environment. The adverse health effects resulting from exposure to particulate matter (PM) are becoming increasingly prominent [3-5], as is the documented presence of problematic PM levels in some indoor environments [613]. Short-term exposure to high concentrations of ambient PM is associated with increased morbidity and mortality due to cardiovascular, respiratory and venous thromboembolic disease [14]. Fine PM is particularly problematic in urban environments, where it is commonly found as black carbon associated with harmful hydrocarbons sourced from diesel emissions [15]. Fine PM, with an aerodynamic diameter of $<2.5 \mu \mathrm{m}\left(\mathrm{PM}_{2.5}\right)$, can penetrate deeply into the lung and therefore has greater health effects than coarser particles [16].

Elevated indoor PM concentrations can occur through the transfer of outdoor generated particles to the indoor environment as well as through the emission or resuspension of indoor sourced particles. Outdoor generated PM can enter the building through ventilation systems or natural ventilation, such as windows and doors. In numerous cases, indoor PM concentrations closely correlate with the concentration patterns of proximal outdoor PM concentrations [17-19]. Consequently, the prevalence of health effects resulting from indoor PM exposure correlates with outdoor PM concentrations, despite the fact that most human PM exposure occurs in the indoor environment [20]. This trend reflects the inefficiencies of heating, ventilation and air conditioning (HVAC) systems, as common commercial systems can only filter a proportion of PM from influent air. HVAC PM filters commonly used in building ventilation systems, such as MERV 4, 6, 10 and 11 filters, have removal efficiencies of $0-20 \%$ across a range of particle sizes [21], and although more efficient filters are available [22], increased efficiency is met with greater energy use, higher maintenance, and reduced sustainability [23], while still remaining incapable of capturing gaseous pollutants.

Indoor sourced particles also pose a health concern for individuals, as increased building occupancy density and human activities such as smoking, solid fuel stove use and cooking emit PM, and activities such as cleaning can lead to particle re-suspension [8, 24, 25]. Indoor generated particles contribute to $10-30 \%$ of the total burden of disease from PM exposure [19]. The combined effect of indoor and outdoor sourced particles can result in indoor PM concentrations that are higher than outdoor concentrations [17]. Irrespective of origin, technology that mitigates and reduces inhalable particles and other air pollutants within the indoor airspace is crucial for creating a healthy indoor environment.

As an alternative to existing mechanical air conditioning systems, several studies have revealed the promising potential of potted-plants to phytoremediate several indoor air pollutants; mainly volatile organic compounds (VOCs) [26-32] and carbon dioxide $\left(\mathrm{CO}_{2}\right)$ [33-35]. Relatively few studies have assessed the ability of potted-plants to phytoremediate PM in the indoor environment. Lohr and PearsonMims [36] found that potted-plants were able to accumulate PM through foliar interception, and suggested that plants with rough leaf structures such as trichomes 
may be more efficient at intercepting PM than smooth-surfaced vegetation. 102 Gawronska and Bakera [37] showed that the foliage of Chlorophytum comosum 103 (spider plant) was capable of collecting PM across a range of particle sizes, and concluded that more than simple gravitational forces influence PM accumulation on foliage. Neither of these studies, however, measured the effect that this accumulation had on ambient air quality and are thus of limited value as predictors of likely phytoremediation capabilities.

Recent advancements in botanical biofiltration may provide a practical means by which to quantifiably reduce indoor ambient PM concentrations. This technology, known as active green walls or active botanical biofilters, involves the active transfer of PM polluted air through a plant growth substrate using some form of mechanical air transfer, rather than simply relying upon gravitational and diffusive PM deposition. Irga et al. [38] compared the PM removal efficiency of an active green wall to a biofilter with only packing medium, noting that the botanical component of these systems influenced filtration efficiency. While these findings identified the importance of the botanical component of active biofilters in PM removal, Irga et al's [38] use of a single plant species does not indicate whether there are specific plant traits influencing filtration efficiency. It is possible that PM filtration capabilities may vary between plant species due to varying physiology or other traits, as has been shown for other indoor pollutants, for example, Torpy et al. [34] found that the selection of plant species influences the removal of $\mathrm{CO}_{2}$ from indoor air. In particular, plant roots will affect the air filled porosity of the substrate / packing media, thus altering the properties of the filtration matrix [39], suggesting that variability may occur amongst plant types, and that species may be identified that can produce more efficient systems.

This study investigates a range of common green wall plant species in an active botanical biofilter to elucidate the influence of plant type on PM removal efficiency. The specific aims of this research were to:

1. Determine the most efficient plant wall species for active green wall biofiltration of a range of particle fractions.

2. Assess correspondence between PM filtration efficiency and a range of plant factors.

3. Characterise the influence of the botanical component on pressure drop through active green walls.

\subsection{Methods}

\subsection{Description of botanical biofilter and plant species}

The study uses a modular green wall described by Irga et al. [38]. The system consists of a $0.25 \mathrm{~m}^{2}$ polyethylene module with 16 holes on the front face from which plants grow. Airflow enters the system via an electric axial impeller that draws air through the rear of the system and returns it to the indoor environment through the planted surface. The study assessed seven plant species (Table 1) that grow well in the vertical alignment that the biofilter module uses and are widely used by the vertical gardening industry. All tests were conducted on biofilter modules with plants that had been established within the system for more than a year. Additionally, a procedural control consisting of a biofilter lacking botanical components was added as a treatment, to allow the quantification of the effects of substrate separate from the 
effects of the botanical component. Biofilter modules were irrigated to field capacity 24 hours before trials were conducted.

Table 1. Plant species used in this experiment to assess single pass removal efficiency.

\begin{tabular}{|c|c|c|c|}
\hline Species name & $\begin{array}{l}\text { Common } \\
\text { name }\end{array}$ & Clade & Image \\
\hline $\begin{array}{l}\text { Chlorophytum } \\
\text { orchidastrum }\end{array}$ & Fire flash & Monocot & \\
\hline Ficus lyrata & Fiddleleaf fig & Eudicot & \\
\hline Nematanthus glabra & $\begin{array}{l}\text { Goldfish } \\
\text { plant }\end{array}$ & Eudicot & \\
\hline $\begin{array}{l}\text { Nephrolepis cordifolia } \\
\text { duffii }\end{array}$ & $\begin{array}{l}\text { Lemon button } \\
\text { fern }\end{array}$ & Monilophyte & \\
\hline $\begin{array}{l}\text { Nephrolepis exaltata } \\
\text { bostoniensis }\end{array}$ & Boston fern & Monilophyte & \\
\hline Schefflera amate & Umbrella tree & Eudicot & \\
\hline Schefflera arboricola & $\begin{array}{l}\text { Dwarf } \\
\text { umbrella tree }\end{array}$ & Eudicot & \\
\hline
\end{tabular}




\subsection{Single pass removal efficiency (SPRE)}

A sealed Perspex chamber $(0.6 \times 0.6 \times 0.6 \mathrm{~m} ; 216 \mathrm{~L})$ was used in these experiments (Figure 1). To allow the placement of green wall modules into the chamber, one of the sides of the chamber was removed and sealed again after module placement with adhesive foam rubber and adjustable metal clamps. Ducting was fixed to the centre of one side of the chamber. The fitted ducting led to a combustion chamber in which PM was generated by burning $4 \mu \mathrm{L}$ of filtered retail-grade diesel fuel (Shell) absorbed onto a $1 \mathrm{~cm}^{2} 536: 201280 \mathrm{gsm}$ square of paper. The generated PM flowed through the fitted ducting with active airflow provided by an axial impeller (FANTECH TEF-100 fan 16W) housed within the ducting, before flowing through the green wall module where pollutant-containing air is dispersed across the back of the biofilter by the module's plenum. A fan within the Perspex chamber encouraged dispersion of the filtered airflow throughout the chamber to reduce precipitation of particles before exhaust into another ducting system fixed to the opposite side of the chamber, which led to an additional chamber containing a laser nephelometer (Graywolf PC-3016A, Graywolf Sensing Solutions, Connecticut, USA) to record average particle density and size distribution of the filtered airstream. Air was exhausted to waste through a vacuum exhaust after sampling. Trials for each replicate were recorded for 10 minutes, which was sufficient time for the PM concentration to return to ambient levels for all treatments. For each replicate, average $\mathrm{PM}$ concentration was recorded for five mutually exclusive PM fractions: $\mathrm{PM}_{0.3-0.5}$, $\mathrm{PM}_{0.5-1.0}, \mathrm{PM}_{1.0-2.5}, \mathrm{PM}_{2.5-5.0}$, and $\mathrm{PM}_{5.0-10.0 \text {; }}$ as well as total suspended particles (TSP). An a priori power analysis was conducted utilising pilot data to determine that a sample size of 15 independent replicates per treatment was adequate to provide meaningful comparisons at alpha $=0.05$.

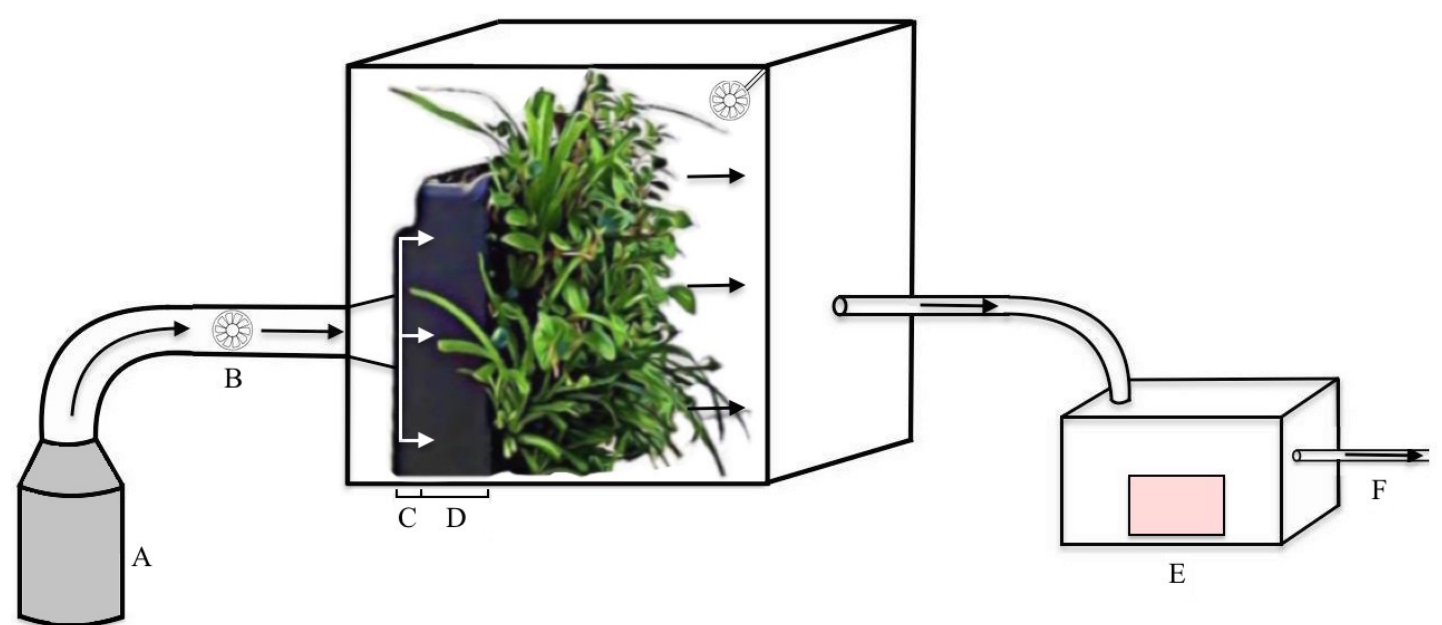

Figure 1. Single pass flow-through chamber described in section 2.2. $\mathrm{A}=$ combustion chamber; $B=$ axial impeller; $C=$ plenum within green wall module; $D=$ green wall packing medium; $E$ = laser nephelometer; $F=$ vacuum exhaust.

Biofilter trials were compared to control data obtained using the same process without any green wall module in the chamber. This procedure was replicated 27 times to provide an accurate measure of PM distribution and concentration from our PM generation method (supplementary table 1). The following equation thus allowed the calculation of SPRE: 
Equation 1:

$$
\frac{\left([P M]_{\text {control }}-[P M]_{\text {trial }}\right)}{[P M]_{\text {control }}} \times 100=\mathrm{SPRE}
$$

\subsection{Plant morphological data}

Following PM removal trials, plant morphological data was obtained by deconstructing the system and removing the botanical components. For each plant species, average root diameter and leaf width were recorded using callipers, by taking four composite measurements from each plant, from four plant replicates per species.

Roots were washed free from soil and fresh root mass and fresh leaf mass were recorded to obtain average values for each opening of the modules front face. Dry weights of root and leaf mass were obtained by drying samples in an oven at 60 ${ }^{\circ} \mathrm{C}$ for 1 week.

Root surface area was calculated using an adapted version of the method described by Tagliavini et al. [40]. Briefly, for each replicate measurement, plant roots were washed free from soil, blotted dry and set between two sheets of clear Perspex with roots spread out between the sheets. A sheet of white paper was laid under the bottom Perspex sheet, which was backlit by LED lights. A camera lens (Canon $1100 \mathrm{D} 18 \mathrm{~mm}$ lens) was placed $\sim 100 \mathrm{~cm}$ vertically above at a perpendicular angle to the Perspex sheets and roots, thus ensuring negligible parallax error across the image, and images were taken for each replicate. For each image taken, the program Fiji Image J $1.50 \mathrm{~g}$ (National Institutes of Health, USA) was used to determine root surface area by converting the image to a binary image by setting the grey scale threshold to a value that covered the finest roots of each replicate sample. This resulted in an image with the roots in black and the background in white. The scale of the pixels in each image was calculated through the inclusion of objects with a known surface area randomly dispersed throughout the Perspex sheets, further validating equal scale across the entire image. With the scale set, the total pixel matrix occupied by the root image produced a two dimensional root surface area and this value was multiplied by $\pi$ to obtain a total root surface area (roots were assumed to be cylindrical). Leaf area was obtained using a similar image analysis without this calculation.

\subsection{Pressure drop}

Pressure drop is the resistance to airflow across each biofilter module. The pressure drop for each treatment was determined by flowing air through the biofilters with a FANTECH TEF-100 inline axial fan, which was fitted to a $100 \mathrm{~mm}$ ducting connected to the rear inlet of the biofilter module. This is the same fan that was used to generate active airflow during SPRE experiments outlined in section 2.2. Pressure drop was measured with a Sensirion digital sensor (SDP610 $125 \mathrm{~Pa}$ ) placed between the fan and the biofilter. When air exits the module, it returns to ambient pressure, thus measurements from the digital sensor for gauge pressure at the module's rear opening are equivalent to the pressure difference across the module. Values were recorded every second over a $\sim 2$ minute period for each biofilter treatment, providing an average pressure drop value for each module. 
A one factor PERMANOVA (PAST Ver 3.15) based on a Euclidean distance resemblance matrix was used to compare the average SPRE amongst the biofilters containing the different plant species for each PM fraction. To maintain independence of samples, particle concentrations were categorised into five mutually exclusive bin fractions outlined in section 2.2. Consequently, TSP was excluded from this analysis, as TSP incorporates all PM fractions and would thus be non-independent to the other bin fractions. Post hoc pairwise comparisons amongst treatments were made with Bonferroni adjusted $p$-values.

Data variables were standardized prior to the construction of a Euclidean distance matrix for all plant morphology multivariate analyses. A two dimensional ordination of the Euclidean distance rank orders of similarities among plant species was produced by means of non-metric multidimensional scaling (nMDS; PAST Ver 3.15 ) to visually assess similarities and differences within and between different plant species' morphology. nMDS is a multivariate pattern analysis technique that simultaneously combines information from multiple data variables ('dimensions') into two axes, so that they may be readily visualized and interpreted. Unlike most ordination techniques such as principal components analysis, nMDS uses rank order information derived from the similarity matrix, and is thus highly flexible for different data types. As the nMDS plot is a simple representation of the relationship between samples in the multivariate space created by the axes, interpretation should be made based only on the spatial distance between sample points, where proximal points are similar based on the combined variability in the data set, and distant points are variant based on one or more of the variables. To determine if there were general morphological differences in anatomy and structure between plant species that may influence PM removal efficiency, a multivariate analysis of similarities (ANOSIM) was conducted (PRIMER-E Ver 6.1.6, Primer-E Ltd) using the plant structure variables. To identify which variables made the greatest contributions to the differences between plant species observed in the ANOSIM, a similarity percentages analysis (SIMPER) was conducted.

The influence of pressure drop on SPRE was tested using an ordinary least squares linear regression (IBM SPSS Statistics Ver 21) with the SPRE of TSP used as a surrogate response variable for all PM fractions.

\subsection{Results}

Single pass removal efficiencies for $\mathrm{PM}_{0.3-0.5}, \mathrm{PM}_{0.5-1.0} \mathrm{PM}_{1.0-2.5}, \mathrm{PM}_{2.5-5.0}$, and $\mathrm{PM}_{5.0-10.0}$ across the seven different plant species as well as the non-planted treatment are displayed in Figure 2. These findings indicate that green walls containing $N$. exaltata bostoniensis filtered PM of all size fractions at a higher efficiency than modules containing the other species, whilst the plantless biofilter, and the system containing $F$. lyrata generally demonstrated lower efficiency filtration. PERMANOVA revealed significant differences between treatments ( $p s e u d o-F=7.593$, $p=0.0001)$. Subsequent pairwise comparisons between groups showed $N$. exaltata bostoniensis had a significantly higher SPRE $(p<0.05)$ than $N$. glabra, F. lyrata, $S$. amate, $S$. arboricola, and to the plantless biofilter (supplementary material Table 2). The plantless biofilter had a significantly lower SPRE $(p<0.05)$ than $N$. exaltata bostoniensis, F. lyrata, and C. orchidastrum (supplementary material Table 2). 


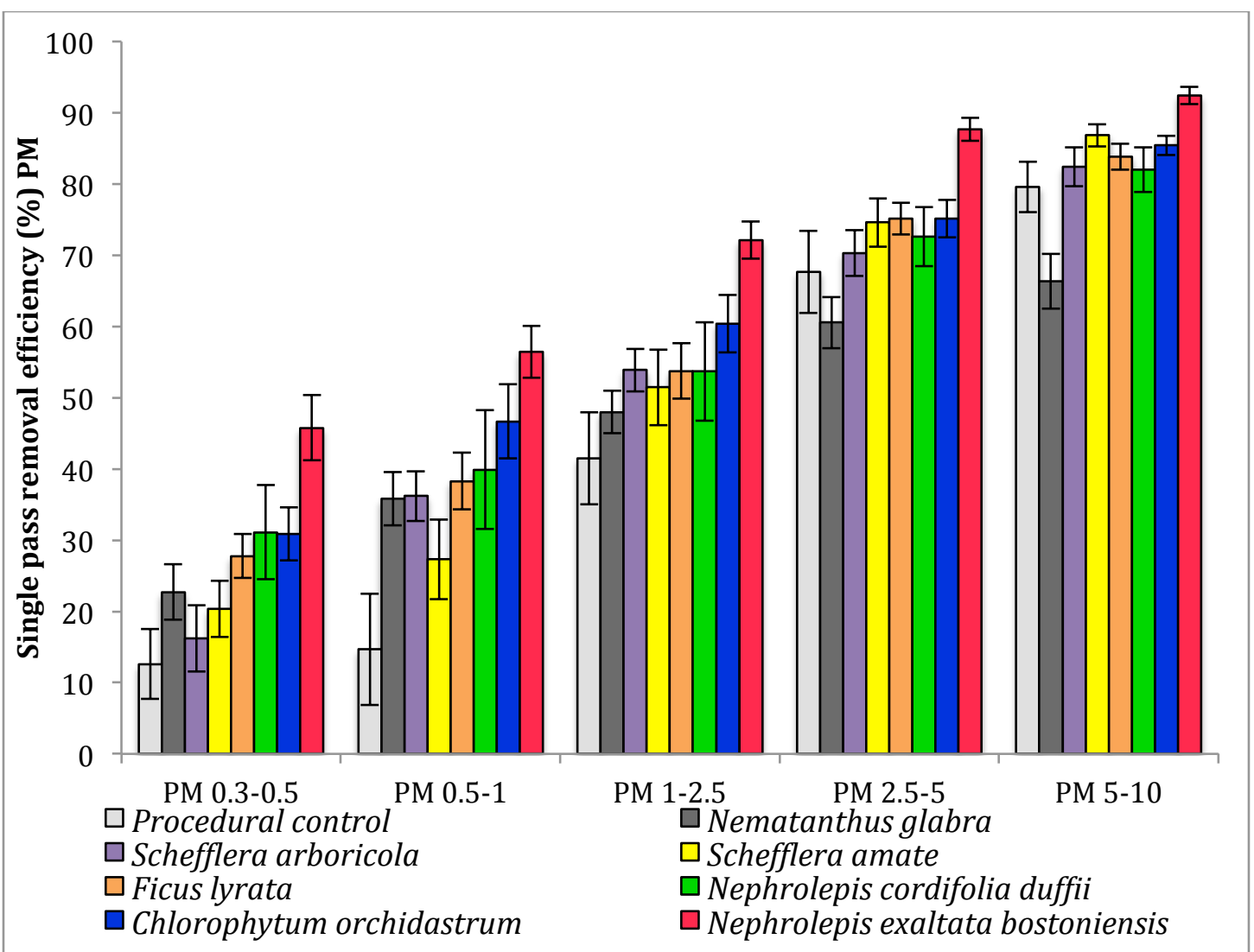

Figure 2. Average single pass removal efficiency (\%) of different treatments used in this experiment across independently sized PM fractions. Error bars represent standard error of the mean $(n=15)$.

A nMDS ordination revealed clear differences between plant species based on their morphological characteristics (Figure 3). It is apparent that variation between different plant species' morphology is much more defined than the variation within each plant species, however the proximity of the points representing the $N$. exaltata bostoniensis samples to the $N$. cordifolia duffii samples suggests a relatively higher degree of similarity between these two species. Despite their similar morphology, these two species performed quite differently, thus the traits that account for these differences in morphology may be important indicators of PM phytoremediation capability.

The nMDS findings were confirmed through ANOSIM (global $R=0.81, p=$ 0.001), indicating a distinction between plant species based on the measured morphological attributes. Pairwise comparisons from the ANOSIM indicated that $S$. amate and S. arboricola; S. amate and F. lyrata; and S. amate and C. orchidastrum did not differ significantly $(p>0.05)$ from one another based on the combined variability in the morphological data variables, however $N$. exaltata bostoniensis displayed significantly different $(p<0.05)$ morphology to all other species. SIMPER was used following the ANOSIM to indicate which plant morphological variables may have accounted for these differences, and thus potentially it's greater ability to filter PM when used in the green walls.

Statistically significant differences in plant morphology were observed amongst the different plant species (Table 2). Although the nMDS ordination suggested that $N$. exaltata bostoniensis and $N$. cordifolia duffii are morphologically similar, a SIMPER analysis assessing plant morphological differences distinguishing $N$. exaltata bostoniensis from $N$. cordifolia duffii, indicated that root 
surface area and dry weight of root mass were the primary morphological traits of species differentiation, respectively contributing to $26.93 \%$ and $23.10 \%$ of the dissimilarity between species.

Table 2. Averages \pm standard error of the mean for plant morphological and pressure drop results across different species.

\begin{tabular}{|c|c|c|c|c|c|c|c|}
\hline Species & $\begin{array}{l}\text { Chlorophytum } \\
\text { orchidastrum }\end{array}$ & $\begin{array}{l}\text { Ficus } \\
\text { lyrata }\end{array}$ & $\begin{array}{l}\text { Nematanthus } \\
\text { glabra }\end{array}$ & $\begin{array}{l}\text { Nephrolepis } \\
\text { cordifolia } \\
\text { duffii } \\
\end{array}$ & $\begin{array}{l}\text { Nephrolepis } \\
\text { exaltata } \\
\text { bostoniensis }\end{array}$ & $\begin{array}{l}\text { Schefflera } \\
\text { amate }\end{array}$ & $\begin{array}{l}\text { Schefflera } \\
\text { arboricola }\end{array}$ \\
\hline $\begin{array}{l}\text { Root } \\
\text { diameter } \\
(\mathrm{mm})\end{array}$ & $3.55 \pm 0.32$ & $4.04 \pm 0.71$ & $0.52 \pm 0.06$ & $0.68 \pm 0.07$ & $0.86 \pm 0.20$ & $4.58 \pm 0.02$ & $3.95 \pm 0.79$ \\
\hline $\begin{array}{l}\text { Root } \\
\text { surface } \\
\text { area }\left(\mathrm{cm}^{2}\right)\end{array}$ & $\begin{array}{l}150.80 \pm \\
20.01\end{array}$ & $\begin{array}{l}173.07 \pm \\
15.06\end{array}$ & $63.71 \pm 28.45$ & $6.92 \pm 0.35$ & $9.63 \pm 1.50$ & $66.25 \pm 8.84$ & $33.6 \pm 4.31$ \\
\hline $\begin{array}{l}\text { Root mass } \\
\text { fresh } \\
\text { weight }(\mathrm{g})\end{array}$ & $13.71 \pm 1.51$ & $6.36 \pm 0.61$ & $1.22 \pm 0.61$ & $3.27 \pm 0.93$ & $5.65 \pm 2.70$ & $13.55 \pm 5.83$ & $16.01 \pm 3.36$ \\
\hline $\begin{array}{l}\text { Root mass } \\
\text { dry weight } \\
\text { (g) }\end{array}$ & $1.76 \pm 0.31$ & $1.93 \pm 0.21$ & $0.33 \pm 0.16$ & $12.62 \pm 2.80$ & $12.81 \pm 3.91$ & $\begin{array}{l}49.49 \pm \\
20.50\end{array}$ & $43.03 \pm 7.22$ \\
\hline $\begin{array}{l}\text { Leaf width } \\
(\mathrm{mm})\end{array}$ & $48.13 \pm 0.34$ & $\begin{array}{l}99.89 \pm \\
3.06\end{array}$ & $14.32 \pm 3.05$ & $0.98 \pm 0.20$ & $1.85 \pm 0.95$ & $2.74 \pm 1.04$ & $3.27 \pm 0.66$ \\
\hline $\begin{array}{l}\text { Leaf } \\
\text { surface } \\
\text { area }\left(\mathrm{cm}^{2}\right)\end{array}$ & $\begin{array}{l}731.17 \pm \\
229.42\end{array}$ & $\begin{array}{l}1335.14 \pm \\
90.28\end{array}$ & $\begin{array}{l}255.63 \pm \\
121.91\end{array}$ & $3.09 \pm 0.64$ & $1.91 \pm 0.46$ & $7.15 \pm 3.44$ & $9.40 \pm 1.73$ \\
\hline $\begin{array}{l}\text { Leaf mass } \\
\text { fresh } \\
\text { weight }(\mathrm{g})\end{array}$ & $26.00 \pm 3.34$ & $\begin{array}{l}32.20 \pm \\
3.09\end{array}$ & $30.22 \pm 16.64$ & $\begin{array}{l}214.42 \pm \\
46.20\end{array}$ & $\begin{array}{l}202.16 \pm \\
45.47\end{array}$ & $\begin{array}{l}195.62 \pm \\
95.25\end{array}$ & $\begin{array}{l}245.63 \pm \\
53.81\end{array}$ \\
\hline $\begin{array}{l}\text { Leaf mass } \\
\text { dry weight } \\
\text { (g) }\end{array}$ & $1.89 \pm 1.25$ & $6.35 \pm 0.39$ & $2.95 \pm 1.53$ & $\begin{array}{l}502.50 \pm \\
142.62\end{array}$ & $\begin{array}{l}913.82 \pm \\
144.51\end{array}$ & $\begin{array}{l}1521.02 \pm \\
558.62\end{array}$ & $\begin{array}{l}1295.32 \pm \\
311.56\end{array}$ \\
\hline $\begin{array}{l}\text { Pressure } \\
\text { drop }(\mathrm{Pa})\end{array}$ & $27.85 \pm 0.12$ & $\begin{array}{l}26.45 \pm \\
0.12\end{array}$ & $23.82 \pm 0.09$ & $27.08 \pm 0.13$ & $29.87 \pm 0.12$ & $25.65 \pm 0.11$ & $25.75 \pm 0.13$ \\
\hline
\end{tabular}




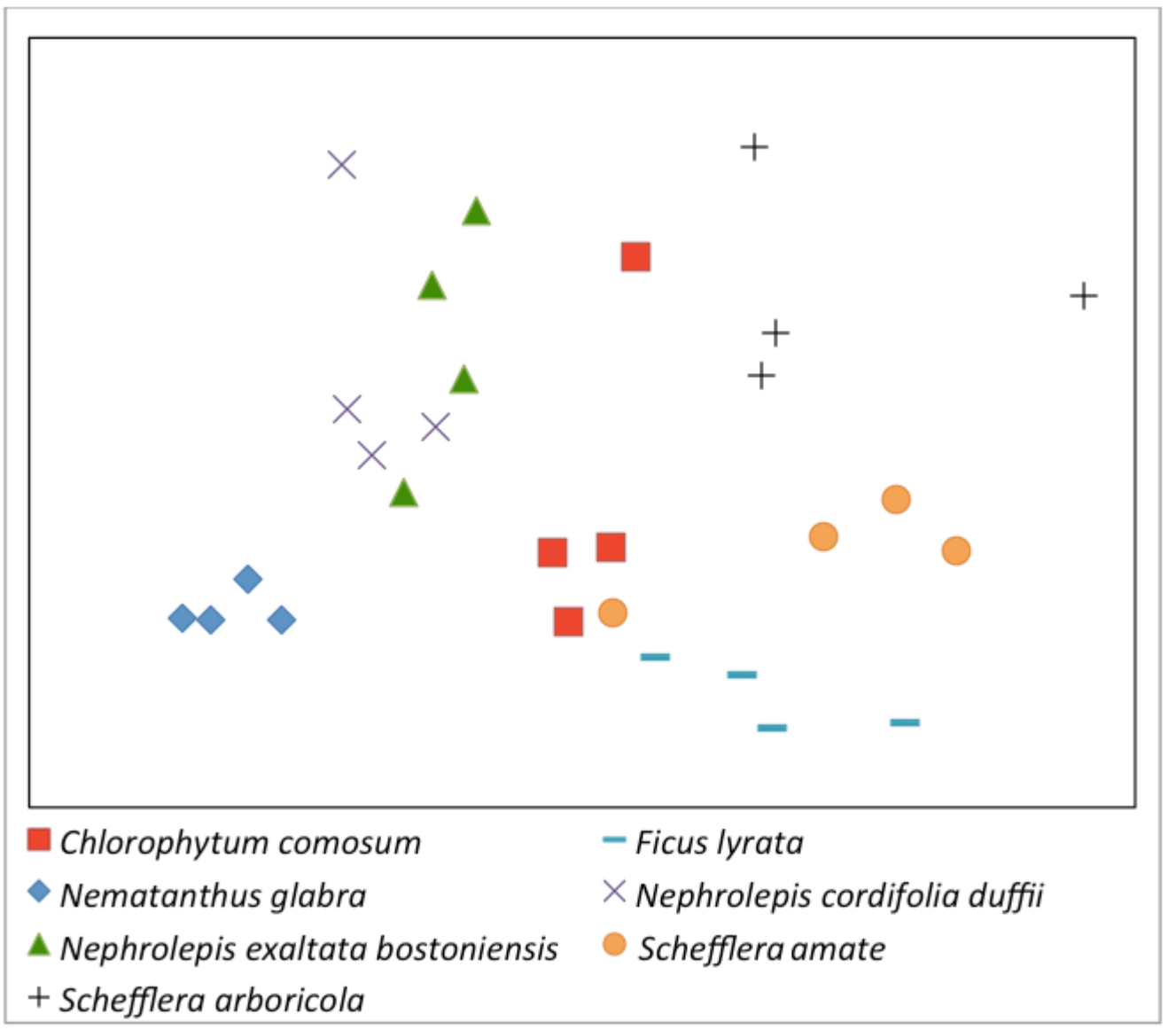

Figure 3. nMDS ordination plot of different plant species based on morphological characteristics; stress $=0.1$.

Visual inspection of plant root structure showed clear differences among the roots of different plant species (Figure 4). N. exaltata bostoniensis and N. cordifolia duffii had dense, matted fibrous roots. C. orchidastrum had few roots with a moderate diameter that were further characterised with thicker nodules and finer fibrous roots. N. glabra also had a short fibrous roots system with a much smaller biomass than all other plant species. S. amate and S. arboricola had branching root systems with roots that had a much larger diameter than the other measured species, whilst $F$. lyrata had a combination of branching roots with fibrous components.

The biofilters containing the different plant species recorded different pressure drops (Table 2), ranging from 23.82 $\mathrm{Pa}$ to $29.87 \mathrm{~Pa}$. An ordinary least squares linear regression found that pressure drop and TSP SPRE had significantly positive relationship across species (Figure 5), with pressure drop accounting for $92.3 \%$ of the variation in TSP SPRE $\left(\mathrm{R}^{2}=0.923, p=0.000\right)$. 

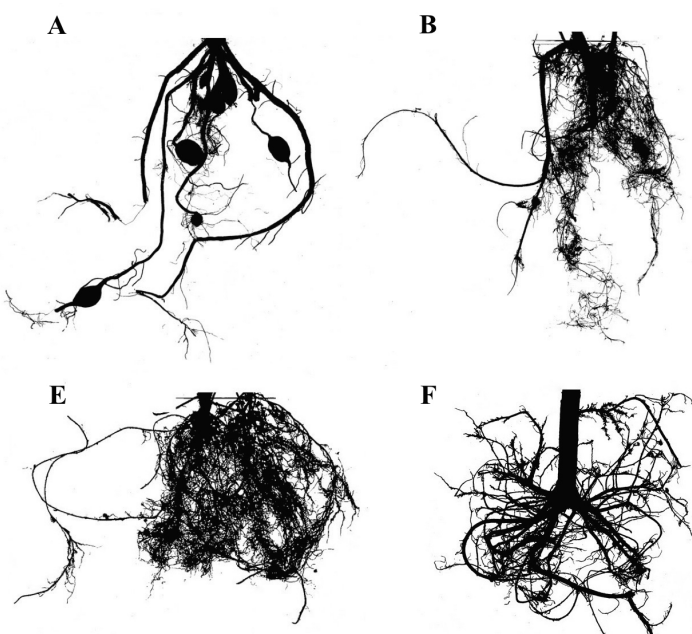

F
C
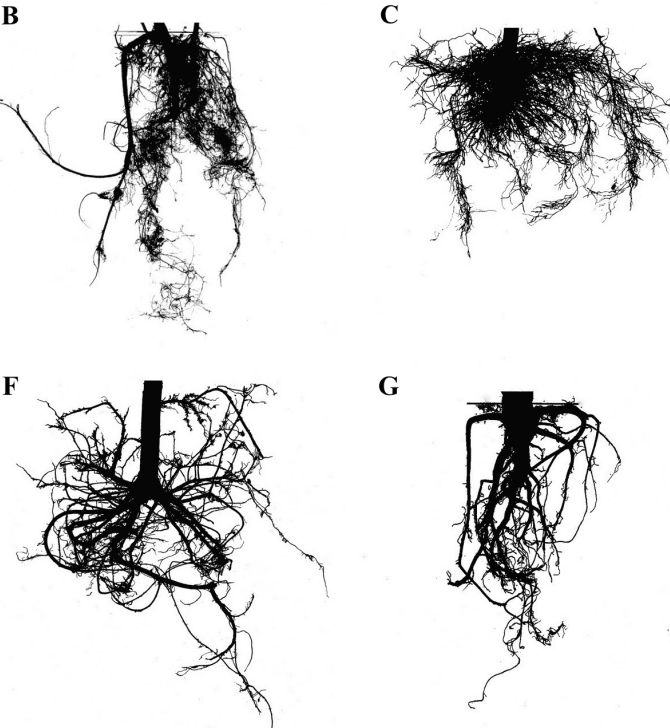

D

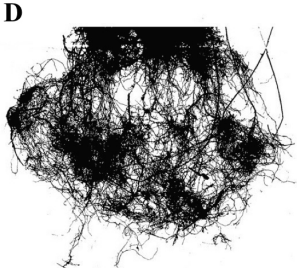

342

Figure 4. Binary example images of plant root structure after disassembling biofilters. $\mathrm{A}=$ Chlorophytum orchidastrum; $\mathrm{B}=$ Ficus lyrata; $\mathrm{C}=$ Nematanthus glabra; $\mathrm{D}=$ Nephrolepis cordifolia duffii; $\mathrm{E}=$ Nephrolepis exaltata bostoniensis; $\mathrm{F}=$ Schefflera amate; $\mathbf{G}=$ Schefflera arboricola . Images are not of equal scale.

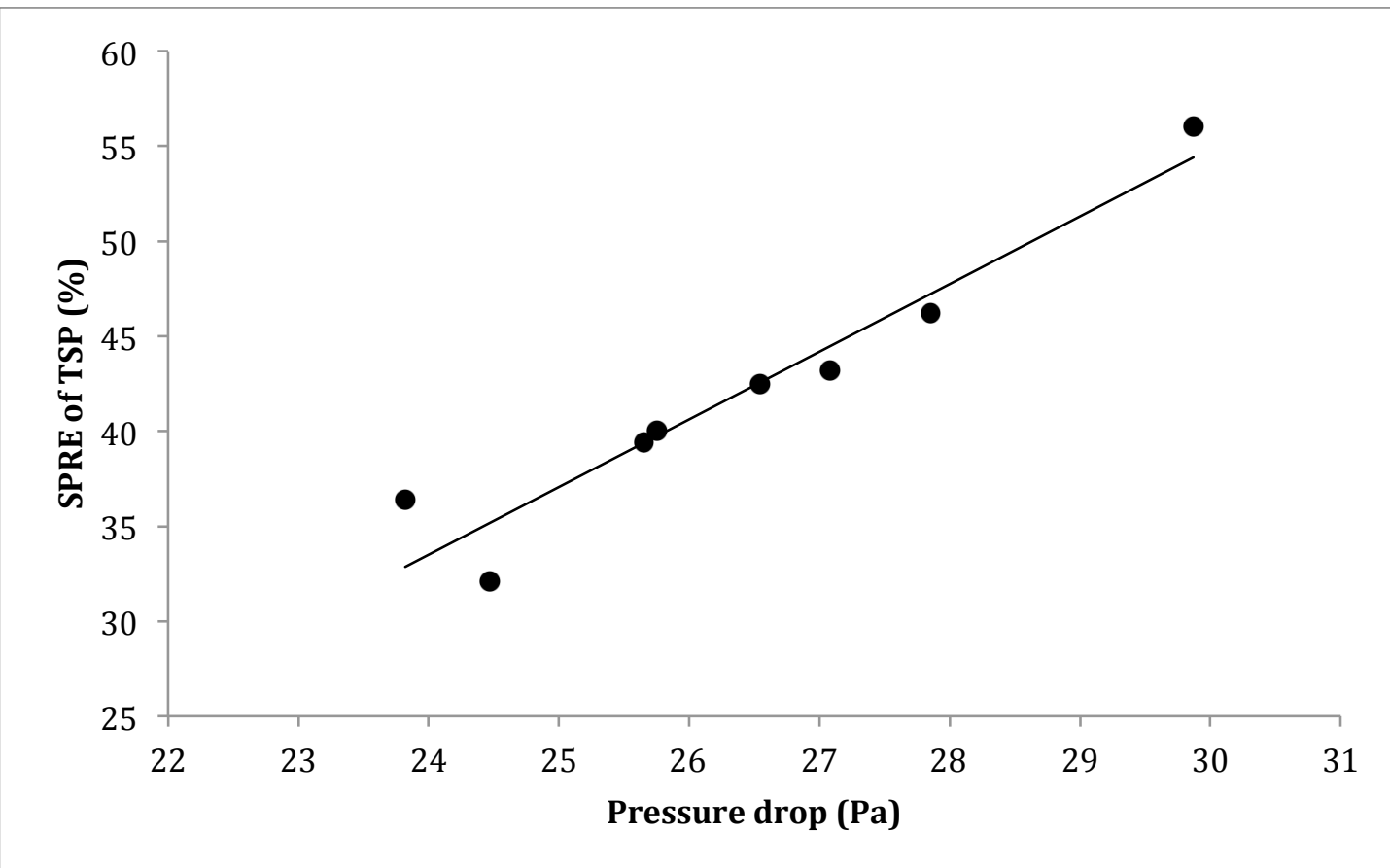

Figure 5. Average pressure drop for each species and control against average TSP SPRE of each species $\left(R^{2}=0.923, p<0.000\right)$.

\subsection{Discussion}

This study has confirmed the potential of active green walls to remove PM from the air, and is the first study of its kind to compare the SPRE across a range of PM fractions in active green wall systems using different plant species. Despite differences in SPRE across treatments, green walls containing all species of plants effectively reduced PM across all tested fractions, and thus would contribute to improved air quality if used in situ. Green walls containing the fern N. exaltata 
bostoniensis, however, outperformed the other species by a significant margin across all PM fractions.

While the substrate clearly plays a key role in filtering PM, the outperformance of the biofilter with no botanical component by all planted treatments indicates that plants clearly play a major functional role in assisting SPRE. This is consistent with the findings of Lee et al. [41], who found that a biofilter that included the plant Diffenbachia amoena had a higher removal efficiency for $\mathrm{PM}_{2.5}$ and $\mathrm{PM}_{10}$ in comparison to a biofilter filled only with soil. While studies that have used passive airflow in potted-plant systems have suggested that plant foliage aids in PM removal $[36,37]$, the corresponding plant morphological data indicates that plant root structure is a much more important component that influences SPRE when combined with active airflow. Irga et al. [38] suggested that the coarse roots of C. comosum reduce the SPRE of biofilters, as these roots may create pores that promote preferential airflow pathways, allowing unfiltered air to pass the biofilter. Conversely, it is possible that roots with different structural anatomy may also modify the substrate structure or physiochemical properties such as to create a biofilter with increased filtration capacity, as observed in this study.

The substrate's ability to act as a PM filter may be altered by different species due to their markedly different root morphological characteristics that reflect the different growth strategies specific to each species. For example, many ferns and herbaceous species develop rhizomes that lead to architecturally simple root systems, while woody plants often form complex root branching systems [42]. The three plants with rhizomatous root structures tested in this study, $N$. exaltata bostoniensis, $N$. cordifolia duffii and C. orchidastrum, have shallow underground root systems and were the higher performing species in terms of SPRE, likely due to a concentration of root biomass towards the surface of the substrate resulting from rhizomatous root growth. This root growth led to a dense mat of roots and compressed substrate that likely increased filtration efficiency and also pressure drop in these treatments (see Figure 4c). While $N$. glabra also exhibited a shallow fibrous root structure, the substantially lower root biomass of this species was insufficient to significantly modify the substrate structural properties, and resulted in this species having a comparatively low SPRE across several PM fractions. In contrast, the eudicot species $S$. arboricola, $S$. amate, and $F$. lyrata, do not exhibit strong rhizomatous growth; rather they produce secondary root growth (thickening) and form relatively large diameter lateral roots from their taproot. Although these three species had the highest dry root weights in this respective order, it is likely that their root structure, characterised by fewer, thicker roots, did not alter the substrate structure in the same manner as the more fibrous roots of $N$. exaltata bostoniensis, $N$. cordifolia duffii and C. orchidastrum. Their root structures, characterised by low-density distribution throughout the depth of the substrate and not constrained to a dense concentration near the biofilter surface most likely lead to their lower filtration efficiencies.

Although this interpretation is supported by the influence of pressure drop on TSP SPRE, it is not currently understood how the combined effects of root competition, gravitropic root growth and proximity to local conditions, such as irrigation and light, influence plant root structure when grown in a vertically aligned substrate [43]. These effects appeared to be stronger in the tree species S. arboricola, $S$. amate, and $F$. lyrata, possibly because these taxa generally do not naturally grow in the comparatively dense colonies in which the fern species are often found [44-46], therefore increasing root competition effects. Whilst all green wall systems tested in the current work used an identical substrate, substrate type will unquestionably have 
its own influence on filtration efficiency, as different substrate types are associated with their own water retention and distribution properties and thus are likely to influence root growth and structure, as well as the substrates' own effects on PM filtration [47]. It is possible that testing different plant species with different substrate types may lead to interacting effects. Similarly, stem gravitropism was much stronger in the tree species, $S$. arboricola, $S$. amate, and F. lyrata, as can be seen in table 1 . Consequently, these species had their leaves arranged so that their leaf lamellae were parallel to the airflow through the module, while $N$. exaltata bostoniensis, $N$. cordifolia duffii and C. orchidastrum, generally grew more horizontally, and their leaves, therefore sat at a perpendicular angle to the airflow through the module, thus promoting greater foliar impaction.

It is likely that the increased pressure drop through root induced substrate mediation led to an increased filtration capacity. With higher pressure drop across the biofilter, air passing through the substrate will experience increased resistance to flow resulting in increased residence time within the substrate and thus increased PM removal efficiency. This is unsurprising as increased resistance to flow is often met with increased SPRE in mechanical ventilation systems [48]. In the case of mechanical filters, increased flow resistance requires an increase in ventilation power to maintain an effective airflow rate across membranes with higher pressure drops [49]. The relatively small differences in pressure drop amongst treatments in the current work, however may lead to a negligible increase in energy use for the most effective variants tested here [50]. Although the results from this study reveal that a higher pressure drop leads to an increase in PM SPRE, it is possible that a high pressure drop could hinder PM remediation in systems that use continual airflow recirculation within the containing room, as an increased pressure drop may lead to a lower volume of air being processed by the system [51]. In any case, it is clear from the current findings that botanical components and species selection in functional, active green walls remains critically important for air quality phytoremediation due to their capacity to remediate numerous indoor air pollutants such as VOCs [29], PM $[37,38]$ and $\mathrm{CO}_{2}$ [34]. Mechanical air filters accumulate dust and other particles over time, which impacts their efficiency by increasing pressure drop and results in the need for frequent filter replacement [48]. However, no study exists that compares the PM filtration efficiency of active green walls over an extended period of time. This clearly needs to be addressed in future studies.

These results have highlighted the PM phytoremediation capacity of active green walls and have elucidated the importance of plant choice for increased pollutant removal of PM. Consideration of the varying phytoremediation abilities of different species across a range of indoor air pollutants such as $\mathrm{CO}_{2}$ [34], formaldehyde [31], toluene and ethyl benzene [52], ozone [53] and PM is important for the development of these systems for increased air quality enhancement capacities. While $N$. exaltata bostoniensis was noteworthy in this study due to its facilitation of high PM SPRE in active green walls, other studies have found it to be one of the most efficient plants in removing benzene [54] and formaldehyde from ambient air [27], whilst Kim et al. [55], who tested 86 plants for their formaldehyde removal efficiency, found that fern species had the highest efficiencies. Although fern species thus appear to be one of the best plants for the phytoremediation of air, there is a paucity of research regarding the differing tolerances of plant species when exposed to various pollutants as well as possible changes in removal rates over time.

This study assessed the potential of active green walls to remediate airborne $\mathrm{PM}$ and has revealed the promising potential of this technology. While there is still 
ample opportunity for further PM SPRE enhancements to the biofiltration system, such as through alterations to substrate composition and thickness, the results of the present work further supports the powerful purification potential of green walls for the removal of airborne particles. Further, the applicability of active green wall systems such as that presented here needs to be validated through implementation in fullscaled rooms in situ with realistic pollutant concentrations. 


\section{References}

[1] N.E. Klepeis, W.C. Nelson, W.R. Ott, J.P. Robinson, A.M. Tsang, P. Switzer, J.V. Behar, S.C. Hern, W.H. Engelmann, The National Human Activity Pattern Survey (NHAPS): a resource for assessing exposure to environmental pollutants, Journal of Exposure Science and Environmental Epidemiology 11(3) (2001) 231.

[2] World Health Organization, Global report on urban health: equitable healthier cities for sustainable development, World Health Organization2016.

[3] R.E. Wyzga, A. Rohr, Long-term particulate matter exposure: Attributing health effects to individual PM components, Journal of the Air \& Waste Management Association 65(5) (2015) 523-543.

[4] S. Feng, D. Gao, F. Liao, F. Zhou, X. Wang, The health effects of ambient PM 2.5 and potential mechanisms, Ecotoxicology and environmental safety 128 (2016) 67-74.

[5] K.J. Maji, A.K. Dikshit, A. Deshpande, Disability-adjusted life years and economic cost assessment of the health effects related to PM2. 5 and PM10 pollution in Mumbai and Delhi, in India from 1991 to 2015, Environmental Science and Pollution Research 24(5) (2017) 4709-4730.

[6] C. He, L. Morawska, J. Hitchins, D. Gilbert, Contribution from indoor sources to particle number and mass concentrations in residential houses, Atmospheric environment 38(21) (2004) 3405-3415.

[7] L. Morawska, C. He, J. Hitchins, D. Gilbert, S. Parappukkaran, The relationship between indoor and outdoor airborne particles in the residential environment, Atmospheric Environment 35(20) (2001) 3463-3473.

[8] L. Morawska, C. He, J. Hitchins, K. Mengersen, D. Gilbert, Characteristics of particle number and mass concentrations in residential houses in Brisbane, Australia, Atmospheric Environment 37(30) (2003) 4195-4203.

[9] H. Fromme, D. Twardella, S. Dietrich, D. Heitmann, R. Schierl, B. Liebl, H. Rüden, Particulate matter in the indoor air of classrooms-exploratory results from Munich and surrounding area, Atmospheric Environment 41(4) (2007) 854-866.

[10] B.J. Tunno, K.N. Shields, L. Cambal, S. Tripathy, F. Holguin, P. Lioy, J.E. Clougherty, Indoor air sampling for fine particulate matter and black carbon in industrial communities in Pittsburgh, Science of the Total Environment 536 (2015) 108-115.

[11] L. Stabile, M. Dell'Isola, A. Russi, A. Massimo, G. Buonanno, The effect of natural ventilation strategy on indoor air quality in schools, Science of The Total Environment 595 (2017) 894-902.

[12] P. Branco, M. Alvim-Ferraz, F. Martins, S. Sousa, Indoor air quality in urban nurseries at Porto city: Particulate matter assessment, Atmospheric environment 84 (2014) 133-143.

[13] A. Challoner, L. Gill, Indoor/outdoor air pollution relationships in ten commercial buildings: PM 2.5 and NO 2, Building and Environment 80 (2014) 159-173.

[14] M.A. Bari, M. MacNeill, W.B. Kindzierski, L. Wallace, M.-È. Héroux, A.J. Wheeler, Predictors of coarse particulate matter and associated endotoxin concentrations in residential environments, Atmospheric environment 92 (2014) 221-230. 
[15] A.C. Rohr, R.E. Wyzga, Attributing health effects to individual particulate matter constituents, Atmospheric Environment 62 (2012) 130-152.

[16] Y.-F. Xing, Y.-H. Xu, M.-H. Shi, Y.-X. Lian, The impact of PM2. 5 on the human respiratory system, Journal of thoracic disease 8(1) (2016) E69.

[17] H. Guo, L. Morawska, C. He, Y.L. Zhang, G. Ayoko, M. Cao, Characterization of particle number concentrations and PM2. 5 in a school: influence of outdoor air pollution on indoor air, Environmental Science and Pollution Research 17(6) (2010) 1268-1278.

[18] L. Morawska, B. Clark, Effect of ventilation and filtration on submicrometer particles in an indoor environment, Indoor air 10(1) (2000) 19-26.

[19] L. Morawska, A. Afshari, G. Bae, G. Buonanno, C.Y.H. Chao, O. Hänninen, W. Hofmann, C. Isaxon, E.R. Jayaratne, P. Pasanen, Indoor aerosols: from personal exposure to risk assessment, Indoor Air 23(6) (2013) 462-487.

[20] W.J. Riley, T.E. McKone, A.C. Lai, W.W. Nazaroff, Indoor particulate matter of outdoor origin: importance of size-dependent removal mechanisms, Environmental science \& technology 36(2) (2002) 200-207.

[21] B. Stephens, J. Siegel, Ultrafine particle removal by residential heating, ventilating, and air-conditioning filters, Indoor Air 23(6) (2013) 488-497.

[22] T.N. Quang, C. He, L. Morawska, L.D. Knibbs, Influence of ventilation and filtration on indoor particle concentrations in urban office buildings, Atmospheric environment 79 (2013) 41-52.

[23] J.F. Montgomery, S.I. Green, S.N. Rogak, K. Bartlett, Predicting the energy use and operation cost of HVAC air filters, Energy and Buildings 47 (2012) 643-650. [24] C.M. Long, H.H. Suh, P. Koutrakis, Characterization of indoor particle sources using continuous mass and size monitors, Journal of the Air \& Waste Management Association 50(7) (2000) 1236-1250.

[25] A.J. Wheeler, N.A. Dobbin, N. Lyrette, L. Wallace, M. Foto, R. Mallick, J. Kearney, K. Van Ryswyk, N.L. Gilbert, I. Harrison, Residential indoor and outdoor coarse particles and associated endotoxin exposures, Atmospheric environment 45(39) (2011) 7064-7071.

[26] T. Godish, C. Guindon, An assessment of botanical air purification as a formaldehyde mitigation measure under dynamic laboratory chamber conditions, Environmental pollution 62(1) (1989) 13-20.

[27] B. Wolverton, J.D. Wolverton, Plants and soil microorganisms: removal of formaldehyde, xylene, and ammonia from the indoor environment, Journal of the Mississippi Academy of Sciences 38(2) (1993) 11-15.

[28] R. Wood, R. Orwell, J. Tarran, F. Torpy, M. Burchett, Potted-plant/growth media interactions and capacities for removal of volatiles from indoor air, The Journal of Horticultural Science and Biotechnology 77(1) (2002) 120-129.

[29] R.L. Orwell, R.L. Wood, J. Tarran, F. Torpy, M.D. Burchett, Removal of benzene by the indoor plant/substrate microcosm and implications for air quality, Water, air, and soil pollution 157(1-4) (2004) 193-207.

[30] R.A. Wood, M.D. Burchett, R. Alquezar, R.L. Orwell, J. Tarran, F. Torpy, The potted-plant microcosm substantially reduces indoor air VOC pollution: I. Office field-study, Water, Air, \& Soil Pollution 175(1) (2006) 163-180.

[31] A. Aydogan, L.D. Montoya, Formaldehyde removal by common indoor plant species and various growing media, Atmospheric environment 45(16) (2011) 2675-2682. 

biostimulation of benzene biodegradation in the potting-mix of indoor plants, Journal of Applied Horticulture 15(1) (2013) 10-15.

[33] P. Irga, F. Torpy, M. Burchett, Can hydroculture be used to enhance the performance of indoor plants for the removal of air pollutants?, Atmospheric environment 77 (2013) 267-271.

[34] F. Torpy, P. Irga, M. Burchett, Profiling indoor plants for the amelioration of high CO 2 concentrations, Urban forestry \& urban greening 13(2) (2014) 227233.

[35] Y.-M. Su, C.-H. Lin, Removal of Indoor Carbon Dioxide and Formaldehyde Using Green Walls by Bird Nest Fern, The Horticulture Journal 84(1) (2015) 6976.

[36] V.I. Lohr, C.H. Pearson-Mims, Particulate matter accumulation on horizontal surfaces in interiors: influence of foliage plants, Atmospheric environment 30(14) (1996) 2565-2568.

[37] H. Gawrońska, B. Bakera, Phytoremediation of particulate matter from indoor air by Chlorophytum comosum L. plants, Air Quality, Atmosphere \& Health 8(3) (2015) 265-272.

[38] P. Irga, N. Paull, P. Abdo, F. Torpy, An assessment of the atmospheric particle removal efficiency of an in-room botanical biofilter system, Building and Environment 115 (2017) 281-290.

[39] P. Abdo, B. Huynh, V. Avakian, T. Nguyen, J. Gammon, F. Torpy, P. Irga, Measurement of air flow through a green-wall module, Measurement 5 (2016) 8. [40] M. Tagliavini, L. Veto, N. Looney, Measuring root surface area and mean root diameter of peach seedlings by digital image analysis, HortScience 28(11) (1993) 1129-1130.

[41] C. Lee, B. Choi, M. Chun, Stabilization of soil moisture and improvement of indoor air quality by a plant-biofilter integration system, Korean Journal of Horticultural Science \& Technology 33(5) (2015) 751-762.

[42] X. Dong, H. Wang, J. Gu, Y. Wang, Z. Wang, Root morphology, histology and chemistry of nine fern species (pteridophyta) in a temperate forest, Plant and soil 393(1-2) (2015) 215-227.

[43] L. Jørgensen, D.B. Dresbøll, K. Thorup-Kristensen, Spatial root distribution of plants growing in vertical media for use in living walls, Plant and soil 380(1-2) (2014) 231-248.

[44] L.F.M. Coelho, M.C. Ribeiro, R.A.S. Pereira, Water availability determines the richness and density of fig trees within Brazilian semideciduous forest landscapes, Acta oecologica 57 (2014) 109-116.

[45] M. Large, L. Farrington, The Nephrolepis Boston fern complex (including Nephrolepis exaltata [L.] Schott), Nephrolepidaceae, naturalised in New Zealand, (2016).

[46] C.W.W. Ng, J. Ni, A. Leung, C. Zhou, Z. Wang, Effects of planting density on tree growth and induced soil suction, Géotechnique 66(9) (2016) 711-724.

[47] L. Jørgensen, D.B. Dresbøll, K. Thorup-Kristensen, Root growth of perennials in vertical growing media for use in green walls, Scientia Horticulturae 166 (2014) 31-41.

[48] K. Owen, R. Pope, J. Hanley, How Do Pressure Drop, Efficiency, Weight Gain, and Loaded Dust Composition Change Throughout Filter Lifetime?, ASHRAE Transactions 120 (2014) 366. 
[49] W.J. Fisk, D. Faulkner, J. Palonen, O. Seppanen, Performance and costs of particle air filtration technologies, Indoor air 12(4) (2002) 223-234.

[50] B. Stephens, A. Novoselac, J.A. Siegel, The effects of filtration on pressure drop and energy consumption in residential HVAC systems (RP-1299), Hvac\&R Research 16(3) (2010) 273-294.

[51] M. Liu, D.E. Claridge, S. Deng, An air filter pressure loss model for fan energy calculation in air handling units, International Journal of Energy Research 27(6) (2003) 589-600.

[52] W. Sriprapat, P. Suksabye, S. Areephak, P. Klantup, A. Waraha, A. Sawattan, P. Thiravetyan, Uptake of toluene and ethylbenzene by plants: removal of volatile indoor air contaminants, Ecotoxicology and environmental safety 102 (2014) 147-151.

[53] O.A. Abbass, D.J. Sailor, E.T. Gall, Effectiveness of indoor plants for passive removal of indoor ozone, Building and Environment 119 (2017) 62-70.

[54] Y.-J. Liu, Y.-J. Mu, Y.-G. Zhu, H. Ding, N.C. Arens, Which ornamental plant species effectively remove benzene from indoor air?, Atmospheric Environment 41(3) (2007) 650-654.

[55] K.J. Kim, M.I. Jeong, D.W. Lee, J.S. Song, H.D. Kim, E.H. Yoo, S.J. Jeong, S.W. Han, S.J. Kays, Y.-W. Lim, Variation in formaldehyde removal efficiency among indoor plant species, HortScience 45(10) (2010) 1489-1495. 


\section{Supplementary material}

Table 1. Average particle size distribution and concentration obtained from PM generation methods $(n=27)$.

\begin{tabular}{|l|l|l|}
\hline PM fraction & $\begin{array}{l}\text { Average PM concentration } \\
\left(\mu \mathrm{g} / \mathrm{m}^{3}\right)\end{array}$ & Standard error of the mean \\
\hline $\mathrm{PM}_{0.3-0.5}$ & 19.86 & 1.09 \\
\hline $\mathrm{PM}_{0.5-1}$ & 19.66 & 1.22 \\
\hline $\mathrm{PM}_{1-2.5}$ & 45.88 & 3.36 \\
\hline $\mathrm{PM}_{2.5-5}$ & 22.46 & 2.07 \\
\hline $\mathrm{PM}_{5-10}$ & 8.09 & 0.90 \\
\hline Total suspended particles & 142.23 & 5.08 \\
\hline
\end{tabular}

Table 2. Pairwise PERMANOVA comparison matrix comparing PM SPRE of biofilters containing different plant species. $p$ values and $p s e u d o-F$ values are shown respectively for each comparison. Notes: $p$-values are adjusted with Bonferroni correction, ${ }^{* *}$ indicate significant at $1 \%$, and $*$ indicate significant at $5 \%$.

\begin{tabular}{|c|c|c|c|c|c|c|c|}
\hline Treatment & $\begin{array}{l}\text { Chlorophytum } \\
\text { orchidastrum }\end{array}$ & $\begin{array}{l}\text { Ficus } \\
\text { lyrata }\end{array}$ & $\begin{array}{l}\text { Nematanthus } \\
\text { glabra }\end{array}$ & $\begin{array}{l}\text { Nephrolepis } \\
\text { cordifolia } \\
\text { duffii }\end{array}$ & $\begin{array}{l}\text { Nephrolepis } \\
\text { exaltata } \\
\text { bostoniensis }\end{array}$ & $\begin{array}{l}\text { Schefflera } \\
\text { amate }\end{array}$ & $\begin{array}{l}\text { Schefflera } \\
\text { arboricola }\end{array}$ \\
\hline Ficus lyrata & $1 ; 1.137$ & & & & & & \\
\hline $\begin{array}{l}\text { Nematanthus } \\
\text { glabra }\end{array}$ & $0.168 ; 6.896$ & $\begin{array}{l}0.285 \\
5.196\end{array}$ & & & & & \\
\hline $\begin{array}{l}\text { Nephrolepis } \\
\text { cordifolia } \\
\text { duffii }\end{array}$ & $1 ; 0.4285$ & $1 ; 0.1005$ & $1 ; 2.002$ & & & & \\
\hline $\begin{array}{l}\text { Nephrolepis } \\
\text { exaltata } \\
\text { bostoniensis }\end{array}$ & $0.355 ; 5.936$ & $\begin{array}{c}0.008^{* *} \\
13.49\end{array}$ & $\begin{array}{l}0.002^{* *} ; \\
26.46\end{array}$ & $\begin{array}{l}0.7084 \\
4.991\end{array}$ & & & \\
\hline $\begin{array}{l}\text { Schefflera } \\
\text { amate }\end{array}$ & $1 ; 3.675$ & $1 ; 1.421$ & $0.383 ; 4.546$ & $1 ; 1.112$ & $\begin{array}{l}0.008^{* *} ; \\
15.88\end{array}$ & & \\
\hline $\begin{array}{l}\text { Schefflera } \\
\text { arboricola }\end{array}$ & $1 ; 3.151$ & $1 ; 1.534$ & $0.691 ; 3.381$ & $1 ; 0.9691$ & $\begin{array}{c}0.002^{* *} ; \\
19.04\end{array}$ & $1 ; 0.9295$ & \\
\hline $\begin{array}{l}\text { Procedural } \\
\text { control }\end{array}$ & $0.008^{* *} ; 15.33$ & $\begin{array}{c}0.025^{*} ; \\
11.83\end{array}$ & $0.187 ; 6.658$ & $\begin{array}{c}0.1484 \\
8.057\end{array}$ & $\begin{array}{l}0.002^{* *} ; \\
30.37\end{array}$ & $\begin{array}{l}0.198 ; \\
7.252\end{array}$ & $\begin{array}{l}0.072 \\
8.842\end{array}$ \\
\hline
\end{tabular}

